\title{
KAJIAN SIFAT FISIKA EMPAT TANAH UTAMA DI SUMATERA BARAT
}

\author{
Yulnafatmawita, Asmar, Ari Ramayani \\ Laboratorium Fisika Tanah F akultas Pertanian U niversitas Andalas Padang
}

\begin{abstract}
A research about soil physical study of four main soils found in West Sumatra was conducted in 2006. The research was aimed to determine some soil physical properties of four soil which are mostly found in West Sumatra. The four soil orders assessed were Ultisol from Agricultural Expreriment Station Limau Manis, Oxisol from Lubuk Minturun, Entisol from Tabing Kecamatan Koto Tangah Padang, dan Andisol from Bukik Gompong Kabupaten Solok. The result showed that at the depth of $0-20 \mathrm{~cm}$ soil profile. Ultisol and Oxisol had finer texture than those of Andisol and Entisol. Andisol was dominated by silt while Entisol was dominated by sand particles. Andisol had the lowest bulk density and the highest soil organic matter and total porosity. Soil Organic matter content of Entisol, Oxisol, and Ultisols was low in criteria. Plant available water (PAW) was higher in Oxisol, then followed by Andisol, Ultisol, and Entisol.
\end{abstract}

Key words: Organic matter, bulk density, texture, porosity, plant available water

\section{PENDAHULUAN}

Sifat fisika tanah, salah satu komponen kesuburan tanah, mempengaruhi pertumbuhan tanaman secara lansung maupun tidak lansung. Penetrasi akar, pengambilan hara, penyerapan air, pernafasan akar dan sebagainya lansung dikontrol oleh sifat fisika tanah. Selanjutnya, secara tridak lansung sifat fisika tanah sifat kimia dan biologi tanah. Oleh sebab itu, sifat fisika tanah merupakan hal utama yang harus dipertimbangkan dalam penggunaan lahan bagi pertanian sebelum usaha memperbaiki sifat lainnya.

Beberapa sifat fisika tanah yang mempengaruhi pertumbuhan tanaman diantaranya yaitu tekstur tanah, bobot volume (BV), ruang pori baik total ruang pori (TRP) maupun distribusi pori, serta kandungan bahan organik (BO) tanah. Tekstur tanah adalah salah satu sifat fisika tanah yang relativ tetap. Dengan kata lain, tekstur tanah tidak berubah akibat pengolahan dalam jangka waktu yang pendek, kecuali terjadi pengikisan pada permukaan tanah atau erosi. Pada peristiwa erosi, biasanya partikel halus tanah terutama liat akan tersuspensi dalam air, dan pada daerah yang miring akan hanyut bersama air aliran permukaan ke daerah yang lebih rendah. Dengan demikian, tanah pada daerah lereng atas akan bertekstur lebih kasar dibanding pada lereng bawah atau pada kaki bukit.

Tekstur tanah akan mempengaruhi sifat fisika tanah lainnya seperti BV, TRP, kelembaban tanah, serta struktur tanah. Tanah bertekstur kasar seperti pasir biasanya akan mempunyai nilai BV lebih tinggi dibanding tanah bertekstur halus seperti liat, pada kondisi lain yang sama. Hal ini disebabkan karena satu butir pasir berukuran $2 \mathrm{~mm}$ misalnya merupakan total padatan tanpa ruang pori. Disisi lain, liat yang digabung menjadi gumpalan berukuran 2 $\mathrm{mm}$ akan mempunyai rongga diantaranya. Hal ini disebabkan karena liat tersebut tidak tersusun secara rapi, sangat tergantung pada saat pengeringan airnya. Berdasarkan Koorevar (1972) partikel liat bisa tersusun secara random jika pengeringan dilakukan tiba-tiba ataupun paralel jika pengeringan terjadi bertahap dan perlahan. Pada posisi random, gumpalan liat akan mempunyai jumlah pori yang lebih banyak, sehingga BV tanahnya menjadi lebih kecil dibanding dengan posisi paralel.

Nilai BV tanah akan menentukan tingkat kepadatan suatu tanah serta penetrasi dan perkembangan akar tanaman. Tanah dengan BV yang tinggi pada kelas tekstur 
yang sama akan lebih padat dibanding tanah dengan BV yang rendah. Pada tanah yang padat akar sukar menembus tanah dan berkembang, sehingga fungsinya untuk menyerap hara dan air yang ada dalam tanah tidak maksimal. Akibatnya, pertumbuhan tanaman pada tanah dengan BV tinggi akan terhambat dan kerdil dibanding pada tanah dengan $\mathrm{BV}$ rendah, walaupun tanah tersebut mempunyai kandungan unsur hara yang cukup.

Selanjutnya, nilai BV tanah akan berpengaruh pada total ruang pori tanah. Semakin tinggi nilai $\mathrm{BV}$ tanah semakin rendah total ruang porinya, atau berbanding terbalik. Tanah bertekstur pasir dengan $\mathrm{Bv}$ yang lebih tinggi akan mempunyai total ruang pori yang lebih rendah dibanding tanah bertekstur liat. Akan tetapi, tanah bertekstur kasar akan mempunyai total ruang pori makro yang lebih banyak. Total ruang pori bisa menentukan kapasitas maksimum air teretensi dalam tanah, tetapi tidak menjamin berapa jumlah air bisa tersedia bagi tanaman serta kelancaran sirkulasi udara tanah dengan udara luar yang dikenal dengan aerase tanah. Kelancaran aerase pada suatu tanah sangat penting dalam penyediaan oksigen bagi pernafasan akar tanaman.

Di samping udara, ketersediaan air yang cukup juga dibutuhkan tanaman bagi pertumbuhannya. Air berperan sebagai pelarut dan pembawa hara dari tanah masuk ke dalam tubuh tanaman melalui akarnya. Jumlah air tersedia bagi tanaman ditentukan oleh jumlah pori berukuran antara $2 \mu \mathrm{m}-$ $8.6 \mu \mathrm{m}$ (Sarief, 1986). Distribusi pori tanah ini bisa ditentukan dengan menganalisis kadar air tanah pada energi tertentu $(\mathrm{pF})$ dengan alat pressure plate apparatus atau metoda lainnya. Tanah dengan pori makro yang banyak seperti pasir mempunyai aerase yang bagus, tetapi retensi airnya rendah. Sebaliknya, tanah dengan tekstur halus seperti liat akan mempunyai pori mikro yang banyak, sehingga aerase kurang lancar, tetapi retensi air tinggi. Kondisi yang ideal bagi pertumbuhan tanaman adalah tanah yang mampu menyediakan air dan udara secara seimbang.

Keseimbangan udara dan air dalam tanah dapat diciptakan dengan memodifikasi struktur tanah. Salah satu amelioran yang mampu memperbaiki struktur tanah yaitu dengan penambahan bahan organik ke dalam tanah. Bahan organik mampu memodifikasi pengaruh tekstur. Hal ini disebabkan karena BO berperan sebagai agen pengikat butir tanah, menciptakan struktur remah dan memantapkannya. Struktur remah yang tercipta akan mempunyai ukuran pori yang seimbang antara makro dan mikro. Biasanya struktur tanah yang proses aggregasinya dibantu oleh BO akan tahan terhadap proses pembasahan baik berlahan maupun tiba-tiba. Oleh sebab itu, kondiosinya akan lebih stabil dibanding struktur yang terbentuk dengan agen lain. Pori yang seimbang juga akan mampu mengikat air dan menahan udara dalam tanah dalam kondisi yang seimbang juga. Di samping itu, bahan organik sendiri mampu memegang air melampaui berat bahan itu sendiri.

Berdasarkan uraian diatas diperoleh bahwa sifat fisika tanah merupakan kunci penentu dalam penetapan penggunaan lahan bagi usaha pertanian. Tujuan dari penelitian ini adalah mendeterminasi beberapa sifat fisika empat ordo tanah (Andisol, Entisol, Oxisol, dan Ultisol) yang ada di Sumatra Barat agar tersedia data bagi kepentingan usaha pertanian.

\section{METODA PENELITIAN}

Penelitian ini dilakukan dengan metoda survai. Daerah pengambilan sampel ada 3 lokasi yaitu 1) di Kenagarian Koto Gadang Guguk jorong Bukik Gompong Kabupaten Solok untuk tanah berordo Andisols (Lestari, 2001), 2), di Lubuk Minturun Kecamatan Koto Tangah Padang untuk tanah berordo Entisols (Al-Ikhwanul, 2003) dan Oxisols (Maidhal, 1993), 3) serta di Kebun Percobaan Fakultas Pertanian Unand Limau Manis Padang untuk tanah berordo Ultisols (Fitrisia, 2004). Contoh tanah baik utuh maupun terganggu diambil di semua lokasi di lapangan pada kedalaman 0-20 cm, kemudian dibawa ke laboratorium Fisika Tanah Fakultas Pertanian Unand Padang. Contoh tanah utuh untuk $\mathrm{pF}$ atau kandungan air tersedia dikirim ke laboratorium Ilmu Tanah Fakultas Pertanian 
Universitas Jambi. Contoh tanah terganggu dikering-anginkan dan di haluskan sesuai kebutuhan analisis, $2 \mathrm{~mm}$ untuk analisis tekstur dan $0.5 \mathrm{~mm}$ untuk analisis karbon organik. Analisis tekstur dilakukan dengan menggunakan metoda pipet dan ayakan (Gee and Bowder, 1986), C-organik dengan metoda Walkley and Black (Hakim et al, 1986), BV dan TRP dengan metoda ring sample (Black and Hartge, 1986).

Data yang didapat dari analisis laboratorium, tekstur, bahan organic tanah, serta BV dan TRP, tidak dianalisis secara statistik, melainkan hanya dibandingkan dengan kriteria sifat fisika tanah yang dikeluarkan Lembaga Penelitian tanah (LPT) Bogor tahun 1979.

\section{HASIL DAN PEMBAHASAN}

Contoh tanah dari setiap jenis tanah diambil di lapangan yang tidak diolah atau tanah bekas pengolahan yang sudah lama ditinggalkan. Tanah Entisol diambil di pinggir sungai daerah Parak Buruak, Lubuk Minturun. Daerah ini merupakan dataran banjir yang digenangi banjir secara periodik. Oxisols diambil pada lahan yang ditanami tanaman tua di Lubuk Minturun, serta Ultisol di Kebun Percobaan Faperta Unand Padang yang mempunyai vegetasi semak, karamuntiang dan sawo. Sedangkan contoh tanah Andisol diambil dari Solok, tepatnya di jorong Bukik Gompong kenagarian Koto Gadang Guguak. Daerah pengambilan sampel terdiri dari semak belukar dan kebun campuran.

\section{Tekstur Tanah}

Dari Tabel 1 terlihat bahwa setiap ordo tanah mempunya distribusi partikel yang berbeda. Perbedaan yang signifikan terlihat antara Entisol dengan Andisol dan dengan Oxisol dan Ultisol. Tanah Entisol Parak Buruak Lubuk Minturun ini didominasi oleh partikel pasir yaitu lebih dari $80 \%$, hanya sekitar $20 \%$ berukuran halus atau $<0.05 \mathrm{~mm}$. Partikel halus terutama liat mampu meretensi air dan unsur hara, karena mempunyai permukaan yang luas dan sebagiannya bermuatan. Oleh sebab itu, dengan rendahnya partikel halus pada tanah ini, maka ketersediaan air dan hara bagi tanaman tidak akan tercukupi. Kalaupun lahan ini harus ditanami, daerah ini membutuhkan frekuensi irigasi yang tinggi atau dengan interval yang pendek.

Sebaliknya, tanah Oxisol dan Ultisol mempunyai partikel liat yang jauh lebih tinggi dari debu dan pasir yaitu hampir 60$80 \%$. Hal ini berarti kemampuan retensi air tanah sangat tinggi. Akan tetapi, jumlah air yang tersedia bagi pertumbuhan tanaman tidak liner dengan kemampuan retensi maksimum atau total ruang pori, tetapi ditentukan oleh jumlah pori yang berukuran $2-8.6 \mu \mathrm{m}$. Jika kedua tanah mempunyai struktur yang bukan remah, atau kandungan bahan organik tanah rendah, maka tanah ini akan kekurangan oksigen bagi pertumbuhan tanaman, atau aerase tanah kurang lancar. Pada kondisi yang demikian, pernafasan akar tanaman juga bisa terganggu, dan perkembangan jamur bisa membahayakan tanaman.

Berbeda dari ke tiga tanah diatas, Andisol Bukik Gompong Solok didominasi oleh partikel berukuran halus ( $₫ 0.05 \mathrm{~mm}$ ).

Tabel 1. Hasil analisis distribusi partikel dan klasifikasi tekstur tanah percobaan pada kedalaman $0-20 \mathrm{~cm}$

\begin{tabular}{lrrrr}
\hline Ordo tanah & $\begin{array}{r}\text { Pasir } \\
(\%)\end{array}$ & $\begin{array}{r}\text { Debu } \\
(\%)\end{array}$ & $\begin{array}{r}\text { Liat } \\
(\%)\end{array}$ & $\begin{array}{r}\text { Kelas tekstur } \\
(\text { USDA)* }\end{array}$ \\
\hline Andisols & 4.46 & 61.68 & 33.86 & Lempung liat berdebu \\
Entisols & 80.17 & 2.67 & 17.16 & Pasir berlempung \\
Oxisols & 11.33 & 28.79 & 59.89 & Liat \\
Ultisols & 6.38 & 14.24 & 79.38 & Liat \\
\hline
\end{tabular}

Sumber: * Hardjowigeno (2003) 
Partikel paling banyak yaitu yang berukuran sedang $(0.05-0.002 \mathrm{~mm})$ atau berukuran debu sekitar $62 \%$ dan $34 \%$ berukuran liat. Adanya liat dan debu dari tanah Andisol Bukik Gompong ini mencerminkan jumlah pori makro dan mikro yang cukup bagi retensi dan transmisi air. Dari keempat ordo tanah ini, Andisol memperlihatkan tekstur tanah yang lebih ideal bagi pertumbuhan tanaman, terutama tanaman semusim.

Berbeda dengan $\mathrm{BV}$, nilai TRP tanah menurun dengan peningkatan kadar pasir dalam tanah. Berdasarkan Tabel 2 terlihat bahwa tanah Andisol mempunyai TRP yang termasuk tinggi dalam kriteria, melebihi 3 ordo tanah lainnya dalam penelitian ini. Walaupun demikian, semua tanah mempunyai ruang pori melebihi ruang padatan, dan termasuk kelas sedang. Hal ini berarti bahwa tranah ini tidak padat dan masih bisa digunakan bagi pertumbuhan tanaman. Menurut Buckman dan Brady (1999) bahwa tanah yang ideal kira-kira ruang porinya menempati separoh volume tanah dan kandungan BO nya sekitar 5\%. Ruang pori tersebut diisi oleh air dan udara dalam kondisi seimbang,. Selanjutnya, di samping ditentukan oleh tekstrur, nilai TRP tanah juga dipengaruhi oleh keberadaan $\mathrm{BO}$ dalam tanah. Semakin tinggi BO tanah semakin tinggi pula TRP tanah.

Tanah Andisol yang mempunyai BV terendah dan TRP tertinggi diantaranya mempunyai kandungan BO tanah yang lebih tinggi, yaitu termasuk kriteria sedang. Tingginya kandungan BO tanah Andisol disebabkan oleh mineral liat yang mendominasi tanah ini, yaitu mineral liat alofan. Mineral alofan tidak berbentuk kristal atau tidak berbentuk (amorfus), sehingga mempunyai luas permukaan spesifik yang sangat luas. Dengan demikian, BO dalam bentuk koloid akan terjerap pada permukaan koloid tanah, sehingga memberi warna hitam atau

\section{Nilai BV, TRP, dan Bahan Organik Tanah}

Sifat fisika tanah dari masing-masing jenis tanah seperti tertera pada Tabel 2 terlihat bahwa semua tanah mempunyai nilai BV sekitar $1.0 \mathrm{gcm}-3$, yaitu termasuk kriteria sedang, kecuali tanah Andisol. Andisol dengan kandungan C-organiknya yang lebih tinggi mengakibatkan tanah tersebut mempunyai berat yang rendah persatuan volumenya, karena ringannya bahan organik dibanding bahan mineral dalam menyusun suatu tanah. Sesuai dengan pendapat ahli bahwa salah satu ciri Andisol adalah mempunyai BV yang rendah, $<0.9 \mathrm{gcm}^{-3}$ (Fiantis, 2003). Hal ini disebabkan karena nilai BV secara lansung ditentukan oleh matrik penyusun tanah dan susunan matriks tersebut dalam tanah atau kondisi strukturnya. Sebaliknya, pada penelitian ini nilai $\mathrm{BV}$ tertinggi terdapat pada Entisol, walaupun masih termasuk kriteria sedang atau sama dengan tanah Oxisol dan Ultisol. Tingginya BV Entisol berhubungan erat dengan tekstur tanah yang didominasi oleh partikel pasir (Tabel 1).

Tabel 2. Hasil analisis BV, TRP, dan BO empat ordo tanah di Sumatra Barat

\begin{tabular}{lccc}
\hline Ordo Tanah & $\begin{array}{c}\text { Berat Volume } \\
\text { Tanah }\left(\mathrm{g} \mathrm{cm}^{-3}\right)\end{array}$ & $\begin{array}{c}\text { Total Ruang Pori } \\
\text { Tanah }(\%)\end{array}$ & $\begin{array}{c}\text { Bahan Organik } \\
(\%)\end{array}$ \\
\hline Andisols & $0.64 \mathrm{r}^{* *}$ & $74.85 \mathrm{t}$ & $5.25 \mathrm{~s}$ \\
Entisols & $1.06 \mathrm{~s}$ & $59.12 \mathrm{~s}$ & $2.86 \mathrm{r}$ \\
Oxisols & $0.98 \mathrm{~s}$ & $62.32 \mathrm{~s}$ & $2.47 \mathrm{r}$ \\
Ultisols & $0.99 \mathrm{~s}$ & $61.87 \mathrm{~s}$ & $2.68 \mathrm{r}$ \\
\hline Sumber : *Lembaga Penelitian Tanah Bogor $(1979) * *$ r $=$ rendah, $\mathrm{s}=$ sedang, $\mathrm{t}=$ tinggi
\end{tabular}


gelap pada tanah. Bahan organik yang tinggi akan melahirkan sifat fisika tanah yang baik pada Andisol. Dengan BO yang banyak tanah menjadi lebih gembur atau BV rendah, TRP menjadi tinggi, distribusi akan seimbang antara makro dan mikro, struktur terbentuk remah, dan stabilitas aggregat menjadi mantap. Kondisi yang demikian sangat ideal bagi pertumbuhan tanaman pertanian semusim, seperti sayur-sayuran, palawija, dsb.

\section{KESIMPULAN}

Hasil analisis sampel tanah pada kedalaman 0-29 $\mathrm{cm}$ dari empat ordo tanah pada beberapa lokasi di Sumatra Barat dapat diambil kesimpulan bahwa:

- Semua tanah yang dianalisis masih mempunyai sifat fisika tanah yang cukup beragam, terutama tekstur tanah dan mempunyai kandungan BO yang rendah kecuali Andisol. Akan tetapi, secara umum sifat fisika tanahnya, tidak termasuk Andisol, belum dikategorikan pada lahan kritis. Andisol mempunyai sifat fisika tanah yang terbaik diantaranya.

- Tekstur tanah paling kasar yaitu Entisol (pasir berlempung), lalu diikuti oleh Andisol (lempung liat berdebu), kemudian Oxisol dan Ultisol (liat).

- Andisol mempunyai BV terendah (0.64 gcm-3), TRP (74.85\%), dan Bahan Organik (5.25\%) tertinggi

\section{DAFTAR PUSTAKA}

Black, G.R. and Hartge, H. 1986. Bulk density. In "Method of Soil Anlysis Part 2: Physical and Mineralogical Methods. $2^{\text {nd }}$ Edition. page 363-376.

Campbell, G.S. and Gee, G.W. 1986. Water potensial: Miscellaneous methods. In "Method of Soil Analysis Part 2: Physical and Mineralogical Methods. $2^{\text {nd }}$ Edition. page 628-630.
Gee, G. W. and Bauder, J. W. (1986). Particle-size analysis. In "M ethods of Soil Analysis" Part 1 Physical and mineralogical Methods, edited by A.Klute, ASA-SSSA Publ., Madison, 383412.

Hillel, D. 1980. Introduction to soil physics. Academic Press, San Diego, 364.

Marshal, T.J., Holmes, J.W., and Rose, C.W. 1996. Soil Physics. $3^{\text {rd }}$ edition, Cambridge University press.

Rusman, B., Yulnafatmawita, and Adrinal. 1993. Ketersediaan Air Tanah Podzolik Merah Kuning Kebun Percobaan Limau Manis Padang.

So, H.B., Kirchhof, G., and Basnet, B.B. 1994. Soil physics laboratory manual. Department of Agriculture The University of Queensland.

Darmawidjaja, M. I. 1980. Klassifikasi Tanah, dasar teori bagi peneliti tanah dan pelaksana pertanian di Indonesia. Balai Penelitian the dan kina Gambung. 259 hal.

Hanks, R.J. and Aschroft, G.L. 1980. Applied Soil Physics. Springer-Verlag. 150 $\mathrm{p}$

Foss, J.E. Moormann, F.R., and Rieger, S. 1983. Inceptisols. In Pedogenesis and soil taxonomy II. The soil orders edited by L.P.Wilding, N.E. Smeck, and G.F. Hall. Elsevier Sci. Publisher, Amsterdam, $410 \mathrm{p}$

Grossman, R.B. 1983. Entisols. In Pedogenesis and soil taxonomy II. The soil orders edited by L.P.Wilding, N.E. Smeck, and G.F. Hall. Elsevier Sci. Publisher, Amsterdam, $410 \mathrm{p}$

Miller, B.J. 1983. Ultisols. In Pedogenesis and soil taxonomy II. The soil orders edited by L.P.Wilding, N.E. 
Smeck, and G.F. Hall. Elsevier Sci. Publisher, Amsterdam, $410 \mathrm{p}$

Wambeke, A.V., Eswaran, H., Herbillon, A.J., and Comerma, J. 1983. In
Pedogenesis and soil taxonomy II. The soil orders edited by L.P.Wilding, N.E. Smeck, and G.F. Hall. Elsevier Sci. Publisher, Amsterdam, $410 \mathrm{p}$

\section{Lampiran}

1. Deskripsi profil dan analisis contoh tanah Ultisols

$\begin{array}{ll}\text { Profil No. } & : 2 \\ \text { Lokasi } & : \text { Kebun Percobaan FPUA } \\ \text { Tanggal Pengamatan } & : 14 \text { Juni 2003 } \\ \text { Deskripsi } & : \text { Ledhy Fitrisia } \\ \text { Klasifikasi } & : \text { Typic Kandiudults, berliat, kaolinitik, } \\ & \text { Isohipertermik } \\ \text { Bahan Induk } & : \text { Berdapan alluvial dan kolluvial } \\ \text { Fisiografi } & : 15^{\circ} \\ \text { Lereng } & : 320 \mathrm{~m} \mathrm{dpl} \\ \text { Elevasi } & : \text { Baik } \\ \text { Draenase } & : \text { Semak Belukar } \\ \text { Penggunaan Lahan } & : \text { Ilalang, pandan duri, Paku resam, sirih } \\ \text { Vegetasi } & \end{array}$

\begin{tabular}{|c|c|l|}
\hline Horizon & $\begin{array}{c}\text { Kedalaman } \\
(\mathrm{cm})\end{array}$ & \multicolumn{1}{c|}{ Uraian } \\
\hline Ap & $0-15$ & $\begin{array}{l}\text { 10 YR 3/4 Coklat gelap kekuningan; liat; gumpal bersudut, } \\
\text { lemah, sedang; konsistensi dalam keadaan lembab, } \\
\text { gembur; perakaran kasar dan halus banyak; pori kasar } \\
\text { banyak, pori halus sedikit; batas horizon baur, } \\
\text { bergelombang. }\end{array}$ \\
\hline E & $15-29$ & $\begin{array}{l}\text { 10 YR 4/6 Coklat gelap kekuningan; liat; gumpal bersudut; } \\
\text { lemah, sedang; konsistensi dalam keadaan lembab, } \\
\text { gembur; perakaran kasar dan halus banyak; pori kasar } \\
\text { banyak, pori halus sedikit; batas horizon baur, } \\
\text { bergelombang. }\end{array}$ \\
\hline BtI & $29-65$ & $\begin{array}{l}\text { 10 YR 5/8 Coklat kekuningan; liat; gumpal bersudut; } \\
\text { lemah, sedang; konsistensi dalam keadaan lembab, } \\
\text { gembur; perakaran kasar dan halus sedang, pori kasar } \\
\text { banyak, pori halus sedikit; batas horizon baur, terputus. }\end{array}$ \\
\hline Bt2 & $65-116$ & $\begin{array}{l}\text { 10 YR 4/6 coklat gelap kekuningan; liat; gumpal bersudut; } \\
\text { lemah, sedang; konsistensi dalam keadaan lembab, } \\
\text { gembur; perakaran kasar dan halus sedang; pori kasar } \\
\text { sedang, pori halus banyak; batas horizon baur, terputus. }\end{array}$ \\
\hline $\mathrm{C}$ & $>116$ & $\begin{array}{l}\text { 5 YR 5/8 (coklat kekuningan);liat; gumpal bersudut, } \\
\text { lemah, sedang; konsistensi dalam keadaan lembab, } \\
\text { gembur; perakaran kasar dan halus sedikit; pori kasar } \\
\text { sedang, pori halus banyak; batas horizon baur, terputus. }\end{array}$ \\
\hline
\end{tabular}

Sumber : Fitrisia (2003) 
Analisis sifat Ultisols di Laboratorium

2. Deskripsi Profil Andisols

\begin{tabular}{|c|c|c|c|c|c|}
\hline \multirow{3}{*}{ Macam Analisis } & \multicolumn{5}{|c|}{ Lapisan dan kedalam } \\
\hline & Ap & $\mathrm{E}$ & Bt1 & $\mathrm{Bt} 2$ & $\mathrm{C}$ \\
\hline & $0-15$ & $15-29$ & $29-65$ & $65-116$ & $>116$ \\
\hline Tekstur & & & & & \\
\hline Pasir & 13.17 & 6.24 & 6.92 & 21.02 & 31.04 \\
\hline Debu & 13.91 & 14.76 & 12.29 & 18.01 & 15.56 \\
\hline Liat & 72.93 & 79.00 & 80.79 & 60.97 & 53.40 \\
\hline $\mathrm{pH} \mathrm{H} \mathrm{H}_{2} \mathrm{O} 1: 1$ & 5.68 & 5.43 & 5.32 & 5.43 & 5.27 \\
\hline $\mathrm{pH} \mathrm{H} \mathrm{H}_{2} \mathrm{O}$ & 5.22 & 4.77 & 4.74 & 4.70 & 4.53 \\
\hline Bahan Organik (\%) & 9.50 & 4.92 & 3.29 & 2.77 & 2.25 \\
\hline C-Organik (\%) & 5.51 & 2.85 & 1.91 & 1.61 & 0.31 \\
\hline N-Total (\%) & 0.252 & 0.14 & 0.112 & 0.118 & 0.014 \\
\hline $\mathrm{C} / \mathrm{N}$ & 21.86 & 20.35 & 17.05 & 13.64 & 22.14 \\
\hline Berat Volume $\left(\mathrm{BV}=\mathrm{g} \mathrm{cm}^{-3}\right)$ & 1.55 & 1.74 & 1.77 & 1.99 & 1.86 \\
\hline $\mathrm{P}_{2} \mathrm{O}_{5}$ dalam Bray II $(\mathrm{ppm})$ & 11.451 & 15.887 & 18.943 & 19.817 & 17.388 \\
\hline Kation dapat dipertukarkan & 1657 & 0231 & 0184 & 0104 & 0161 \\
\hline $\operatorname{Mg}($ meq. \%) & 1.666 & 0.414 & 0.359 & 0.120 & 0.249 \\
\hline $\mathrm{K}$ (meq.\%) & 0.619 & 0.304 & 0.294 & 0.178 & 0.273 \\
\hline $\mathrm{Na}$ (meq.\%) & 0.895 & 0.567 & 0.753 & 0.496 & 0.646 \\
\hline Total Kation & 4.837 & 1.516 & 1.59 & 0.898 & 2.227 \\
\hline KTK Tanah (meq.\% tanah) & 14.4 & 8.8 & 9.6 & 7.2 & 13.6 \\
\hline KTK Liat (meq.\% Liat) & 17.00 & 11.13 & 11.88 & 11.80 & 19.85 \\
\hline Kejenuhan Basa (\%) & 36.094 & 10.523 & 10.325 & 5.476 & 7.636 \\
\hline Al-dd (meq.\%) & 0.903 & 3.192 & 5.36 & 4.356 & 9.417 \\
\hline Kejenuhan $\mathrm{Al}(\%)$ & 1.869 & 25.457 & 42.533 & 51.685 & 60.311 \\
\hline
\end{tabular}

No. Profil

Lokasi

Surveyor

Lereng

Topografi

Bentuk Wilayah

Elevasi

Bahan Induk Tanah

Drainase

Penggunaan Lahan

Vegetasi

Klasifikasi Tanah
$: 5$

: Bukit Gompong

: Silvi Lestari

: $16 \%$

: Miring

: Lereng Tengah Vulkanik

: $1180 \mathrm{~m} \mathrm{dpl}$

: Vulkanik Andesit

: Sangat Baik

: Kebun Kulit Manis

: Ambuang-ambuang, krinju

: Hapludands (Soil Taxonomy 1994) 


\begin{tabular}{|c|c|c|}
\hline Horizon & $\begin{array}{l}\text { Kedalaman } \\
(\mathrm{cm})\end{array}$ & Uraian \\
\hline Ap & $0-14$ & $\begin{array}{l}5 \text { YR 3/2 (Coklat gelap kemerahan); debu; } \\
\text { remah, halus, lemah; sangat gembur (kondisi } \\
\text { lembab);pori makro dan mikro banyak; } \\
\text { perakaran makro dan mikro banyak; batas } \\
\text { horizon jelas dan rata. }\end{array}$ \\
\hline A 2 & $14-33$ & $\begin{array}{l}5 \text { YR 4/6 (merah kekuningan); liat } \\
\text { berdebu;remah,halus,sedang;gembur } \\
\text { (lembab);pori makro dan mikro banyak; } \\
\text { perakaran makro dan mikro banyak; horizon } \\
\text { baur dan rata. }\end{array}$ \\
\hline B1.1 & $33-67$ & $\begin{array}{l}7.5 \text { YR 5/6 (coklat tua); lempung liat } \\
\text { berdebu;gumpal bersudut, halus, } \\
\text { lemah;gembur;pori makro sedang, pori mikro } \\
\text { banyak; perakaran makro dan mikro } \\
\text { sedikit;ditemukan nodul;batas horizon baur dan } \\
\text { rata. }\end{array}$ \\
\hline B1.2 & $67-85$ & $\begin{array}{l}\text { 7.5 YR 5/8 (coklat tua);lempung } \\
\text { berdebu;gumpal bersudut, } \\
\text { halus,lemah;gembur;pori makro dan mikro } \\
\text { sedikit; perakaran mikro dan makro sedikit; } \\
\text { ditemukan nodul dan batuan. }\end{array}$ \\
\hline
\end{tabular}

Sumber : Lestari (2001).

Analisis sifat Andisols di Laboratorium

\begin{tabular}{|c|c|c|c|c|}
\hline \multirow{2}{*}{ Macam Analisis } & \multicolumn{4}{|c|}{ Kedalaman $(\mathrm{cm})$} \\
\hline & $0-14$ & 14-33 & $33-67$ & $>67$ \\
\hline Pasir (\%) & 30.41 & 45.07 & 39.61 & 57.77 \\
\hline Debu $(\%)$ & 39.44 & 43.81 & 56.33 & 37.85 \\
\hline Liat $(\%)$ & 20.70 & 3.57 & 1.45 & 2.80 \\
\hline Liat halus (\%) & 9.45 & 7.58 & 2.61 & 2.20 \\
\hline Berat Volume $\left(\mathrm{g} \mathrm{cm}^{-3}\right)$ & 0.52 & 0.54 & 0.47 & \\
\hline Permeabilitas $(\mathrm{cm} / \mathrm{jam})$ & \multicolumn{4}{|l|}{18.32} \\
\hline Melanik indeks & 2.00 & 1.00 & 0.01 & 0.10 \\
\hline $\mathrm{pH} \mathrm{H}{ }_{2} \mathrm{O}$ & 6.44 & 6.35 & 6.23 & 6.44 \\
\hline $\mathrm{pH} \mathrm{KCl}$ & 4.46 & 5.24 & 5.57 & 5.59 \\
\hline $\mathrm{pH} \mathrm{NaF}$ & 9.9 & 10.2 & 10.3 & 10.3 \\
\hline P-retensi (\%) & 92 & 95 & 96 & 94 \\
\hline Ca-dd (me/100 g) & 2.19 & 0.91 & 0.57 & 0.50 \\
\hline Mg-dd (me/100 g) & 0.37 & 0.03 & 0.03 & 0.03 \\
\hline K-dd (me/100 g) & 0.23 & 0.15 & 0.05 & 0.10 \\
\hline $\mathrm{Na}-\mathrm{dd}(\mathrm{me} / 100 \mathrm{~g})$ & 0.27 & 0.65 & 0.26 & 0.27 \\
\hline Total Kation & 3.06 & 1.74 & 0.91 & 0.90 \\
\hline KTK tanah $(\mathrm{me} / 100 \mathrm{~g})$ & 63.18 & 14.28 & 20.83 & 16.63 \\
\hline
\end{tabular}




\begin{tabular}{|l|l|l|l|l|}
\hline Al-dd & $\mathrm{Tu}$ & $\mathrm{Tu}$ & $\mathrm{Tu}$ & $\mathrm{Tu}$ \\
\hline Kejenuhan basa (\%) & 4.84 & 12.18 & 4.37 & 5.41 \\
Kejenuhan Aluminium (\%) & - & - & - & - \\
\hline Bahan Organik (\%) & 23.12 & 23.8 & 21.79 & 18.65 \\
C-Organik & 13.4 & 13.8 & 12.64 & 10.82 \\
\hline
\end{tabular}

\section{Deskripsi Profil Oxisols}

$\begin{array}{ll}\text { Surveyor } & : \text { Maidhal } \\ \text { Lokasi } & : \text { Lubuk Minturun } \\ \text { Famili tanah USDA } & : \text { Oxisols } \\ \text { Bentuk Wilayah } & : \text { Berombak } \\ \text { Lereng } & : 3-8 \% \\ \text { Bahan induk } & : \text { Abu Vulkan } \\ \text { Drainase } & : \text { Baik } \\ \text { Penggunaan Lahan } & : \text { Alang-alang, kebun }\end{array}$

\begin{tabular}{|c|c|l|}
\hline Horizon & Kedalaman $(\mathrm{cm})$ & \multicolumn{1}{c|}{ Uraian } \\
\hline A & $0-21$ & $\begin{array}{l}\text { Coklat tua kemerahan (5 YR 5/8), berliat, gumpal } \\
\text { halus lemah, gembur (lembab), pori mikro banyak, } \\
\text { pori makro cukup, perakaran sedang banyak, } \\
\text { perakaran halus banyak, batas horizon baur. }\end{array}$ \\
\hline B21 & $21-60$ & $\begin{array}{l}\text { Coklat kemerahan(5 YR 3/3),berliat, gumpal halus } \\
\text { sedang, gembur (lembab), pori mikro banyak, pori } \\
\text { makro sedikit, perakaran halus banyak, perakaran } \\
\text { sedang cukup, batas horizon baur. }\end{array}$ \\
\hline B22 & $60-115$ & $\begin{array}{l}\text { Coklat tua (10 YR 3/3), liat, gumpal, sedang, lemah, } \\
\text { gembur, pori mikro banyak, pori makro sedikit, } \\
\text { perakaran halus sedikit,sedang sedikit, batas } \\
\text { horizon baur. }\end{array}$ \\
\hline B3 & $115-150$ & $\begin{array}{l}\text { Coklat tua (10 YR 3/4) liat, gumpal, gembur, pori } \\
\text { mikro banyak, pori makro cukup, perakaran halus } \\
\text { sedikit, perakaran sedang tidak ada.. }\end{array}$ \\
\hline
\end{tabular}

Sumber : Maidhal (1993)

Analisis sifat Oxisols di Laboratorium

\begin{tabular}{|l|r|}
\hline Tekstur (\%) & 16.67 \\
Pasir & 5.33 \\
Debu & 78.00 \\
\hline Liat & 2.82 \\
\hline Bahan Organik (\%) & 0.75 \\
\hline Kerapatan Isi $\left(\mathrm{gcm}^{-3}\right)$ & 71.83 \\
\hline TRP $(\%)$ & 7.08 \\
\hline Permeabilitas & \\
(cm/jam) & \\
\hline Daya pemegang air $(\%$ & 65.72 \\
vol) pF 1.00 & 57.97 \\
pF 2.01 & 51.75 \\
pF 2.54 & 36.17 \\
\hline
\end{tabular}




\begin{tabular}{|l|l|}
\hline Kemantapan agregat & 39.34 \\
\hline
\end{tabular}

Analisis Karakteristik Entisols

\begin{tabular}{|l|l|}
\hline Surveyor & $:$ Al-Ikhwanul Khairi \\
\hline Lokasi & $:$ Tabing, Kecamatan Koto Tangah Padang \\
\hline Ordo tanah & $:$ Entisols \\
\hline Drainase & $:$ Agak cepat \\
\hline Lereng & $: 2 \%$ \\
\hline Tingkat bahaya erosi & $:$ Sangat rendah \\
\hline Altitude & $: 2$ m dpl \\
\hline Bahaya banjir & $:$ Tidak ada \\
\hline
\end{tabular}

Analisis Tanah

\begin{tabular}{|l|l|}
\hline Tekstur & $:$ Pasir \\
\hline Kedalaman efektif & $: 63 \mathrm{~cm}$ \\
\hline KTK tanah & $: 4,8 \mathrm{me} / 100 \mathrm{~g}$ \\
\hline pH tanah & $: 6,4$ \\
\hline Salinitas & $: 0,33 \mathrm{mmhos} / \mathrm{cm}$ \\
\hline Total N & $: 0,09 \%$ \\
\hline $\mathrm{P}_{2} \mathrm{O}_{5}$ & $: 13,3 \mathrm{ppm}$ \\
\hline $\mathrm{K}_{2} \mathrm{O}$ & $: 0,99 \mathrm{ppm}$ \\
\hline
\end{tabular}

Sumber : Al Ikhwanul (2003) 